\title{
Minimal detection and low biological fluctuation of mitochondrial CpG methylation at the single-molecule level
}

4 Chloe Goldsmith ${ }^{1 *}$, Jesús Rafael Rodríguez-Aguilera², Ines El-Rifai ${ }^{1}$, Adrien Jarretier ${ }^{1}$, Valérie

$5 \quad$ Hervieu$^{3}$, Victoria Chagoya de Sánchez ${ }^{2}$, Robert Dante ${ }^{4}$, Gabriel Ichim ${ }^{5}$ and Hector

6 Hernandez-Vargas ${ }^{1 *}$

Affiliations:

1. Department of Tumor Escape, Resistance and Immunity. TGF-beta and immuno-regulation Team. Cancer Research Centre of Lyon (CRCL), Inserm U 1052, CNRS UMR 5286, Université de Lyon, Centre Léon Bérard, 28 rue Laennec, 69373 Lyon CEDEX 08, France.

2. Department of Cellular Biology and Development, Instituto de Fisiología Celular, Universidad Nacional Autónoma de México (UNAM), Circuito Exterior s/n, Ciudad Universitaria, Coyoacán 04510, Cd. Mx., Mexico.

3. Department of Surgical Pathology, Hospices Civils de Lyon, Groupement Hospitalier Est, Lyon, France.

4. Dependence Receptors Cancer and Development Laboratory, Department of Signaling of Tumoral Escape. Cancer Research. Center of Lyon (CRCL), Inserm U 1052, CNRS UMR 5286, Université de Lyon, Centre Léon Bérard, 28 rue Laennec, 69373 Lyon CEDEX 08, France.

5. Cancer Cell Death Laboratory, Part of LabEx DEVweCAN, Université de Lyon, Lyon, France. Cancer Research Centre of Lyon (CRCL), Inserm U 1052, CNRS UMR 5286, Université de Lyon, Centre Léon Bérard, 28 rue Laennec, 69373 Lyon CEDEX 08, France.

ORCID IDs: HHV: 0000-0001-6045-2103; JRRA: 0000-0003-1474-6826; VCS: 0000-0001-8577-1186; GI: 0000-

\section{* Corresponding Authors}

chloe.goldsmith@inserm.fr ; hector.hernandez-vargas@lyon.unicancer.fr

29 Department of Tumor Escape, Resistance and Immunity. TGF-beta and immuno-regulation

30 Team. Cancer Research Centre of Lyon (CRCL), Inserm U 1052, CNRS UMR 5286, UCBL1.

31 Centre Léon Bérard, 28 rue Laennec, 69373, Lyon, CEDEX 08, France. 
Abstract

Cytosine DNA methylation in the $\mathrm{CpG}$ context $(5 \mathrm{mCpG})$ is associated with the transcriptional status of nuclear DNA. Due to technical limitations, it has been less clear if mitochondrial DNA ( $\mathrm{mtDNA}$ ) is methylated and whether $5 \mathrm{mCpG}$ has a regulatory role in this context. The main aim of this work was to develop and validate a novel tool for determining methylation of mtDNA and to corroborate its existence across different biological contexts. Using long-read nanopore sequencing we found low levels of $\mathrm{CpG}$ methylation (with few exceptions) and little variation across biological processes: differentiation, oxidative stress, and cancer. $5 \mathrm{mCpG}$ was overall higher in tissues compared to cell lines, with small additional variation between cell lines of different origin. Although we do show several significant changes in all these conditions, $5 \mathrm{mCpG}$ is unlikely to play a major role in defining the transcriptional status of mitochondrial genes.

\section{Keywords}

46 Nanopore sequencing, DNA methylation, mtDNA, metabolism, hepatocytes, differentiation,

47 oxidative stress, $5 \mathrm{mC}$, long-read sequencing.

\section{Introduction}

50 It has long been established that mitochondria are the powerhouse of our cells. They are 51 responsible for producing ATP through the electron transport chain, contributing to the cellular

52 energetic and redox homeostasis (Porporato et al., 2018). In addition, mitochondria have many

53 other functions including the regulation of apoptotic pathways as well as storing calcium for cell

54 signaling (Porporato et al., 2018). The number of mitochondria in a single cell can vary widely;

55 some cells having no mitochondria, such as red blood cells, while other cells can have

56 hundreds, like liver cells (Alberts et al., 2002).

57 Mitochondrial DNA ( $m$ tDNA) has a molecular weight of $16.5 \mathrm{~kb}$ and is comprised of a Heavy

58 Strand (HS) and a Light Strand (LS), with an absence of histones and particular DNA repair

59 requirements (Alexeyev et al., 2013). This unique biology leaves mtDNA exposed to influencing

60 factors from both intra- and extra-cellular origin. For example, reactive oxygen species (ROS)

61 can increase mtDNA copy number (Sun and St John, 2018) and exposure to chemicals can

62 cause mtDNA damage (Weinhouse, 2017). Moreover, alcohol exposure can induce oxidative

63 stress (Lieber, 1991) and increase the expression of mtDNA methyl transferases (mtDNMT1)

64 (Bellizzi et al., 2013). These events highlight the sensitivity of mitochondria to environmental 
factors which can have downstream consequences for cellular respiration as well as cancer development and progression.

67 Regulation of mtDNA gene expression occurs primarily through the Displacement loop (D-

68 loop); a 1200-bp non-coding region of the mitochondrial genome. This region controls

69 mitochondrial replication as well as transcription of its encoded genes through a number of 70 different start sites and promoter regions (Crews et al., 1979; Fish et al., 2004).

71 Among regulatory mechanisms in nuclear DNA, DNA methylation is well characterized and

72 known to be influenced by metabolic activity. In the human genome, cytosine methylation

$73(5 \mathrm{mC})$ occurs mainly in a CpG context (i.e. a cytosine followed by a guanine). However, the existence of mitochondrial cytosine methylation at all has been a topic of debate, with evidence for high levels of mtDNA $5 \mathrm{mC}$ in certain human cells and strand-biased non-CpG methylation (Bellizzi et al., 2013; Dou et al., 2019; Feng et al., 2012; Pirola et al., 2013). However, other studies suggested that some of these findings were due to incomplete bisulfite conversion being caused by a failure to linearize mtDNA prior to sequencing (Hong et al., 2013; Mechta et al., 2017; Owa et al., 2018). Moreover, the tools to analyse the presence of DNA methylation rely heavily on sodium bisulfite conversion and PCR amplification; which damage DNA and can lead to bias (Li and Tollefsbol, 2011).

82 Nanopore sequencing is a unique, scalable technology that enables direct, real-time analysis of long DNA or RNA fragments (Madoui et al., 2015; Seki et al., 2019). It works by monitoring changes to an electrical current as nucleic acids are passed through a protein nanopore. The resulting signal is decoded to provide the specific DNA or RNA sequence. Moreover, this technology allows for the simultaneous detection of nucleotide sequence and DNA and RNA base modifications on native molecules (Jain et al., 2016); hence, removing introduced bias from sodium bisulfite treatment and PCR amplification.

89 The overall aim of this study was to produce conclusive data on the presence or absence of 90 mtDNA CpG methylation (5mCpG) using a novel technique, and to determine its conservation 91 across different biological conditions. Three cellular settings known to influence mitochondrial 92 dynamics were employed: a model of cellular differentiation, cancer and a model of oxidative 93 stress. After enrichment, mitochondria were sequenced using a ONT Minion device and 94 mtDNA methylation status was directly obtained from the raw signals. We observed low levels 95 of strand specific DNA methylation in hepatocytes with consistent changes related to sample 96 origin. 


\section{Results}

\section{$100 \quad$ Nanopore sequencing reliably detects CpG DNA methylation (5mCpG)}

101 Long read sequencing is a rapidly evolving field that is largely still in its infancy. Hence, we first

102 sought to determine the reliability of using nanopore sequencing to detect DNA methylation

103 from native DNA in our own hands. To do so, we sequenced genomic DNA extracted from the

104 human liver cell line HepaRG, using an Oxford Nanopore Minion device (ONT). Global patterns

105 of DNA methylation were consistent with the known depletion of $5 \mathrm{mCpG}$ at $\mathrm{CpG}$ islands (CGIs)

106 (Figure 1A).

A
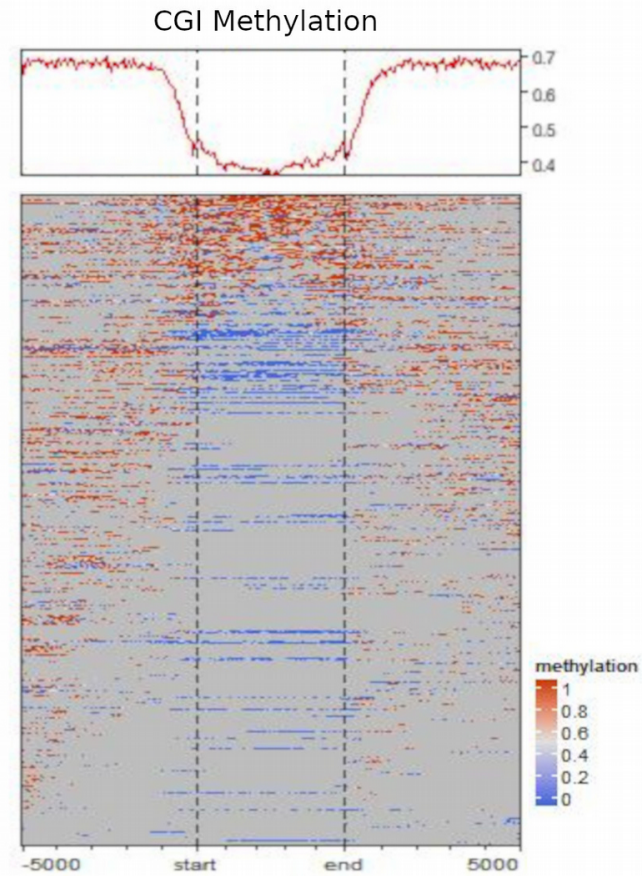

C

beta value correlation

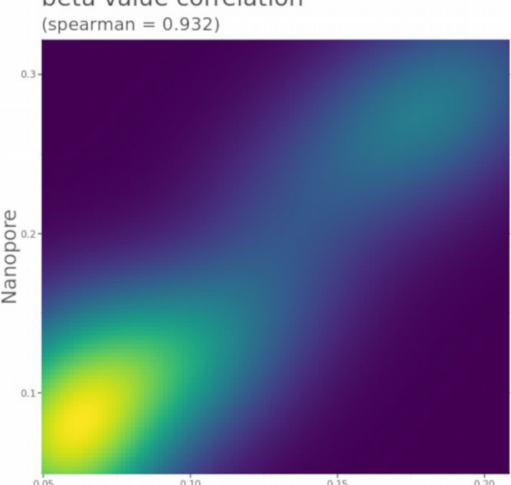

EPIC
B

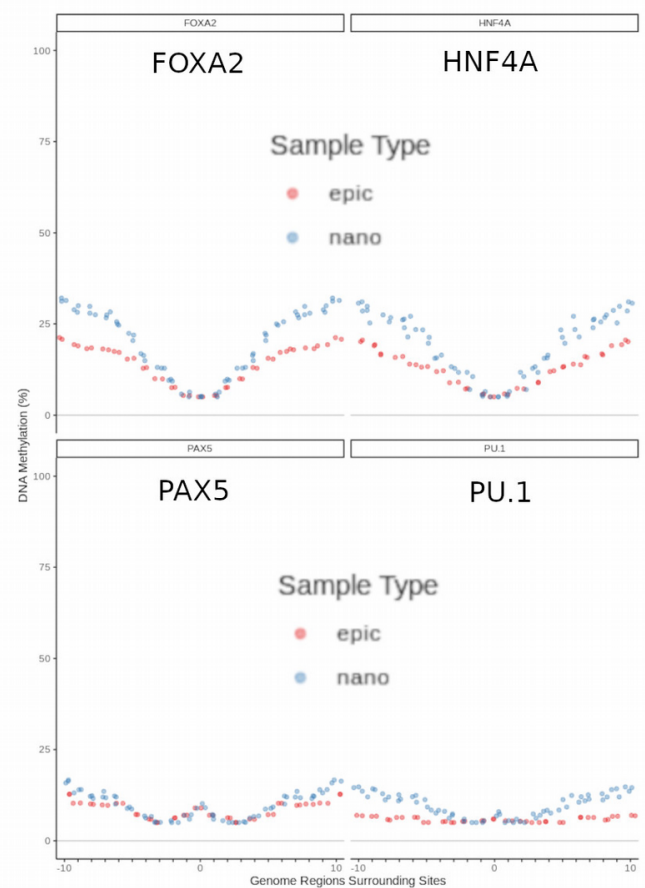

D

Nanopolish versus Medaka (Enriched genes)
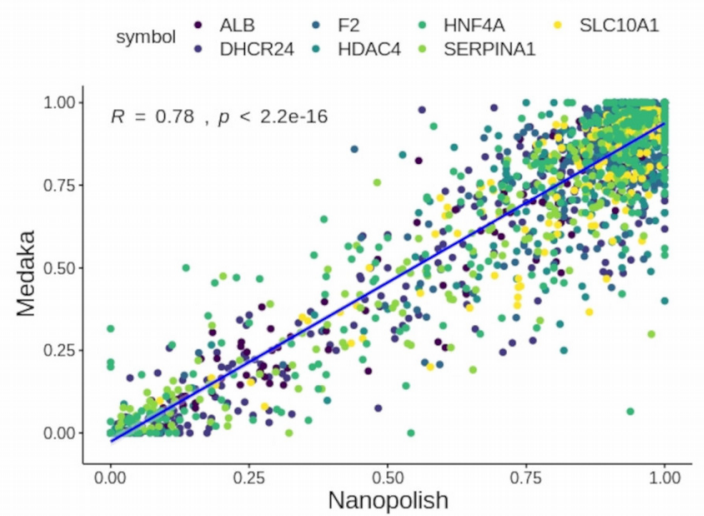
Figure 1. Inspection of 5mCpG data obtained using nanopore sequencing. A) Global profile of nuclear DNA methylation at CpG islands (CGI), obtained after nanopore sequencing of the human liver cell line HepaRG. B) Aggregated DNA methylation data was obtained for hepatocyte active (FOXA2 and HNF4A, top panels) and control (PAX5 and PU.1, bottom panels) transcription factor binding regions. Methylation profiles for EPIC (epic) and Nanopore (nano) (red and blue lines, respectively) are shown for each aggregated dataset. C) EPIC-Nanopore correlation for $5 \mathrm{mCpG}$ data on all aggregated datasets shown in (B). D) Nanopore targeted sequencing for a panel of hepatocyte identity genes was used to basecall $5 \mathrm{mCpG}$ using two different bioinformatic pipelines: Nanopolish and Guppy+Medaka (see Methods). Single CpG level correlations are shown.

We then compared genome-wide methylation patterns of DNA from HepaRG cells sequenced with nanopore, to those obtained with EPIC Bead Arrays (Illumina) (Rodríguez-Aguilera et al., 2020). To overcome the problem of sparsity in DNA methylation data, we aggregated CpG methylation values from more than 130k transcription binding site loci corresponding to

123 hepatocyte-specific (FOXA2 and HNF4A) and control (PAX5 and PU.1) target regions. Both,

124 EPIC and Nanopore data are able to capture the expected dip in methylation associated with

125 active regulatory regions (Figure 1B, top panels) (Lawson et al., 2018). In contrast, non-active 126 transcription factor binding sites produce a flat methylation profile after aggregation of a similar 127 number of genomic regions in both EPIC and Nanopore data (Figure 1B, bottom panels). Both 128 techniques were highly correlated when aggregated data from all transcription factor binding 129 sites was taken together (Figure 1C).

130 Next, we tested different available tools to detect DNA methylation from Nanopore sequencing data. We used the well-established tool, Nanopolish (Simpson et al., 2017) which uses a

132 hidden markov model to detect DNA methylation and compared it to the novel tool Guppy + 133 Medaka which has been trained to basecall for modified human CpG dinucleotides using a 134 recurrent neural network (Wick et al., 2019). To perform a site-level correlation, we used 135 targeted nanopore sequencing data from HepaRG cells with a higher coverage in a set of 136 hepatocyte identity genes (i.e. ALB, F2, HNF4A, SLC10A1, DHCR24, HDAC4 and 137 SERPINA1). Using this method of comparison, DNA methylation values were highly correlated, 138 with Guppy + Medaka having a higher tendency towards calling cytosines as unmethylated 139 (Figure 1D). Nanopolish and Medaka outputs have previously been compared with a slightly 140 higher tendency for Medaka to call unmethylated cytosines. (Gilpatrick et al., 2020); as such, 141 these data are in line with former studies. 
142 Therefore, in agreement with recent publications, $5 \mathrm{mCpG}$ methylation can be reliably obtained

143 from native DNA using nanopore sequencing and different bioinformatic algorithms. For all

144 analyses presented below we used Guppy + Medaka for extraction of $5 \mathrm{mCpG}$ values and

$145 \quad$ Nanopolish for verification and visualization.

\section{Detection of mtDNA $5 m$ CpG in long reads}

148 Having shown the suitability of nanopore sequencing for analysis of nuclear $5 \mathrm{mCpG}$, we used 149 the same strategy on mtDNA enriched by subcellular fractionation of different cell lines (Figure

1502 2). Importantly, mtDNA was linearized enzymatically before sequencing using a Minion

151 device. This technique enabled the clear enrichment of the mitochondrial cellular fraction,

152 measured by protein expression of mitochondrial or cytosolic markers (Figure 2B). After

153 sequencing, we obtained a high fraction of reads mapping to mtDNA. Of note, due to long read

154 length, the proportion of mapped reads and their coverage was higher than $80 \%$. Indeed, some

155 reads consisted of full-length mtDNA sequences (Figure $2 \mathrm{C}$ ). Interestingly, we observed an

156 unequal representation of the heavy strand (HS) and light strand (LS) of mtDNA (Figure 2C).

157 We attributed this to the efficiency of the Bam1 enzyme in its ability to cut the HS more

158 efficiently and leaving a slightly higher ratio of 5' ends available for the ligation of adapters

159 before loading onto the Nanopore sequencing device. Moreover, recent findings suggest there

160 can be an unequal representation of mtDNA CpG methylation on the HS and LS (Dou et al.,

161 2019). Hence, to reduce any potential bias to the average methylation of each CpG site, we

162 considered the methylation of the HS and the LS separately for further analysis. Furthermore,

163 mitochondrial populations can be heterogeneous within a single cell. Therefore, we also took

164 advantage of single molecule methylation, by visualizing the methylation of whole mtDNA reads

165 to better understand the single molecule methylation distribution in our samples.

166 To validate the accuracy of nanopore for detecting $5 \mathrm{mC}$, we prepared fully unmethylated (FU)

167 and fully methylated (FM) mtDNA controls. FU was prepared by whole genome amplification

168 and then FM was prepared by methylation of CpG nucleotides using DNA methyltransferase

169 (M.Sssl). As expected, 5mCpG profiles were opposite in FU and FM mtDNA controls (Figure

$170 \quad 2 \mathrm{C}$ and 2D). Some residual methylation was observed in the FU control and we considered

171 these levels as a baseline for this technique (Figure 2D and 2E). Indeed, we used the FU

172 control as our background to call detectable methylation. This value was obtained by dividing

173 the number of called sites as methylated by the total number of called sites in the FU sample.

174 The background calculated for the mtDNA HS was 0.022 and for the LS 0.016 . We were also

175 able to identify some fully unmethylated reads in the FM control. We attributed this to the

176 efficiency of the DNA methyltransferase (M.Sssl) in methylating these specific reads. 
bioRxiv preprint doi: https://doi.org/10.1101/2020.09.14.296269; this version posted September 14, 2020. The copyright holder for this preprint (which was not certified by peer review) is the author/funder, who has granted bioRxiv a license to display the preprint in perpetuity. It is made available under aCC-BY 4.0 International license.

177 Furthermore, this observation highlights the utility of this approach to identify a mixture of DNA

178 in a single sample.

179

A

$$
\begin{aligned}
& \text { Cell harvesting by scraping } \\
& \text { Dounce homogenizer } \\
& \text { Mitochondria-enriched pellet } \\
& \text { mtDNA extraction } \\
& \text { BamH1 digestion }
\end{aligned}
$$$$
\text { DNA sequencing (MinlON) }
$$

B

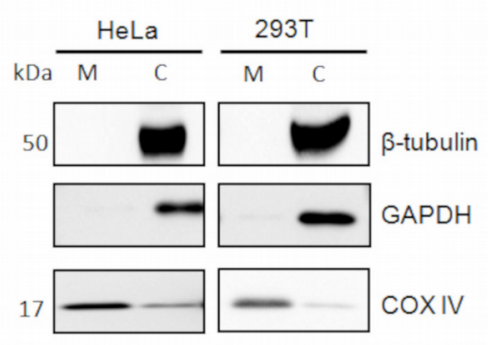

E

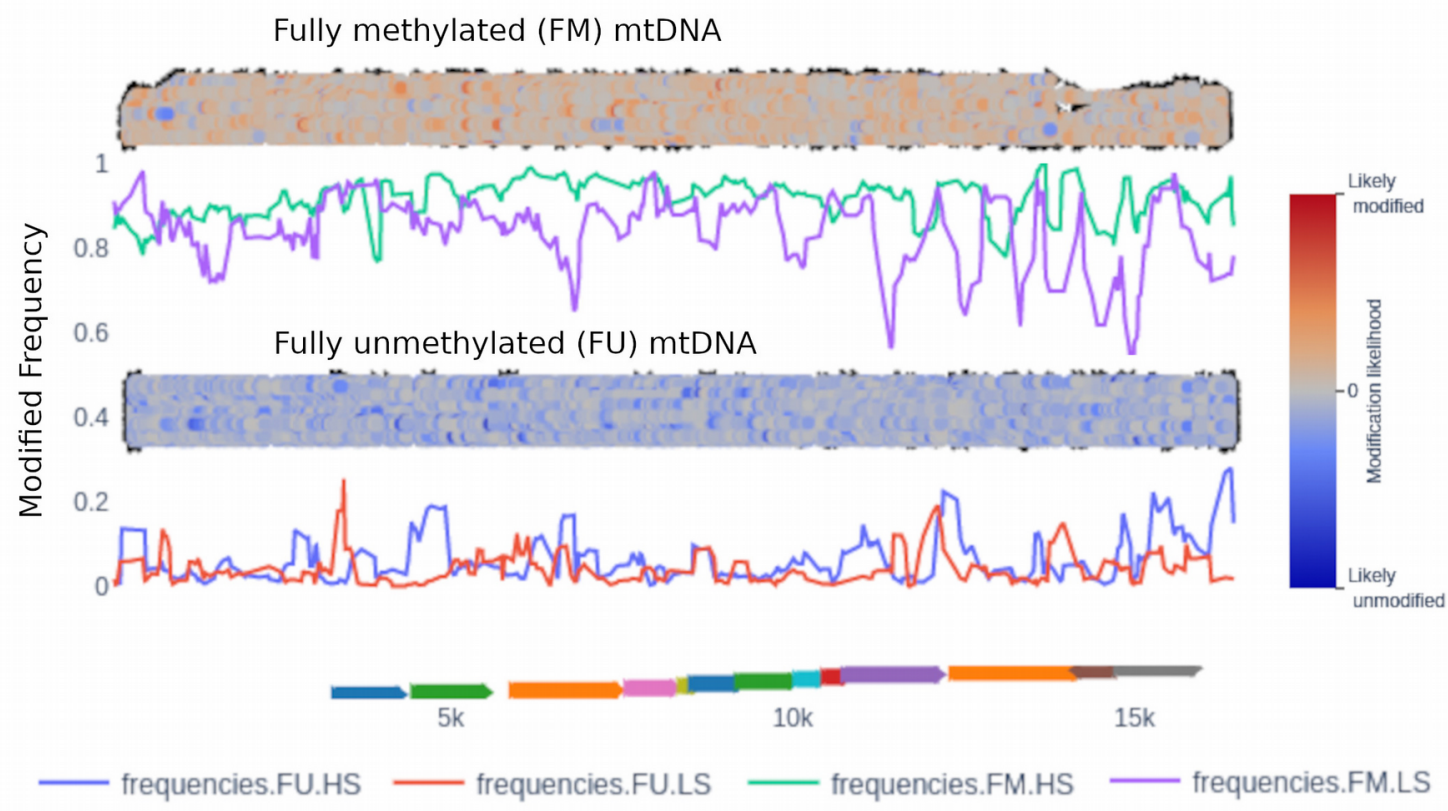

C

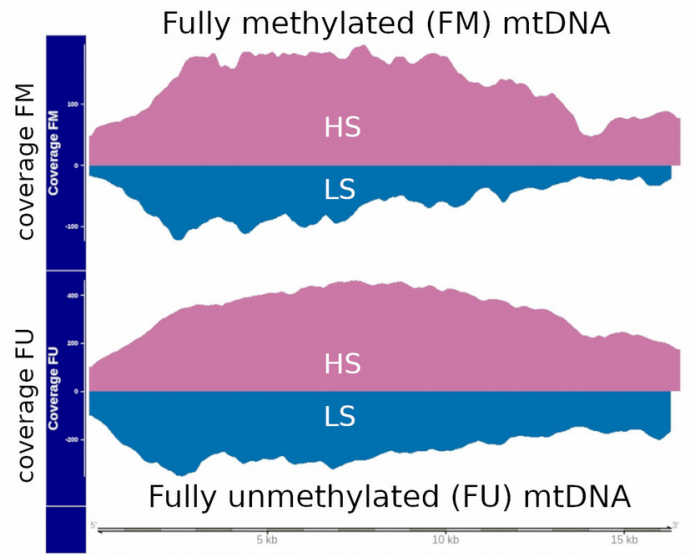

D

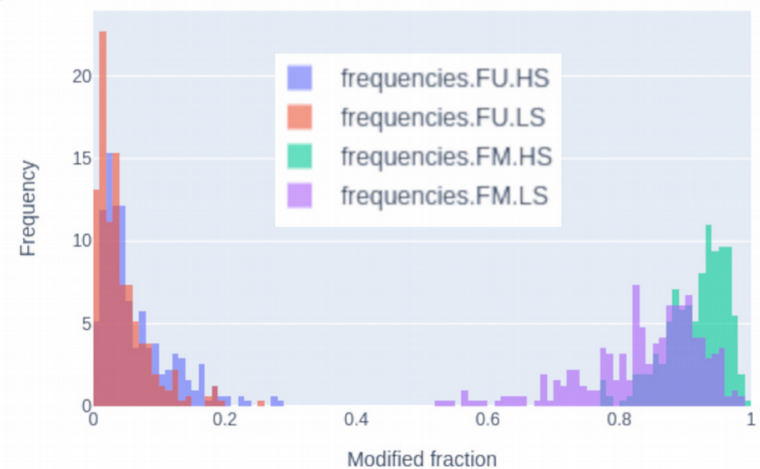


Figure 2. $5 m C p G$ methylation in mtDNA. A) Protocol of subcellular fractionation and $m t D N A$

extraction used before nanopore sequencing. B) Quality control of mtDNA enrichment in different cell lines (i.e. HeLa and 293T) using western blot against b-Tubulin, GAPDH, and COX-IV in mitochondrial (M) and cytosolic (C) fractions.

C) The same protocol was used on the liver cell line HepaRG. In addition, whole genome amplification was used to produce a "fully" unmethylated control (FU), and followed by DNA methylase (M.Sssl) treatment to produce a "fully" methylated control (FM). Nanopore sequencing coverage for the heavy strand (HS) and the light strand (LS) in FU and FM mtDNA-enriched HepaRG samples. D) Nanopolish was used to infer $5 \mathrm{mCpG}$ likelihood and extract methylation frequency tables. Histogram of $5 \mathrm{mCpG}$ frequencies in FU and FM, colored by strand. E) Strand-specific $5 \mathrm{mCpG}$ frequency plots (colored lines), and $5 \mathrm{mCpG}$ likelihood pile-plots (100 reads per sample). Gene mapping to mtDNA are shown in the bottom track as colored arrows.

We observed low basal levels of $5 \mathrm{mCpG}$ in mtDNA from HepaRG cells. Indeed, we did not identify any differential methylation between the FU control and HepaRG cells, either globally or at the CpG site or strand-specific levels (see next Section).

195 These data shows that we are able to detect mtDNA methylation with Nanopore sequencing in FM and FU controls. $5 \mathrm{mCpG}$ is not different from the unmethylated control at HepaRG basal conditions. We next went further to investigate $5 \mathrm{mCpG}$ in several models known to modify mitochondrial activity.

\section{mtDNA methylation was not affected by hepatocyte differentiation}

201 Hepatocyte differentiation implies metabolic rewiring and changes in mitochondrial content and activity (Yu et al., 2012). As such, this dynamic context may involve concomitant changes in mtDNA methylation. The bipotent liver progenitor cells, HepaRG, are capable of in vitro differentiation into hepatocytes and biliary cells. By plating HepaRG cells under differentiating conditions during four weeks we obtain a mixture of the hepatocyte and biliary lineages (Ancey et al., 2017; Cerec et al., 2007; Rodríguez-Aguilera et al., 2020). This well-established model allows us to compare hepatic "progenitor like" cells to their "differentiated" counterpart. We used minimally photo-toxic holo-tomographic microscopy combined with mitochondrial labelling (using MitoTracker Green) to determine mitochondrial content. We observed in both cellular tomogram and MitoTracker staining profile that differentiated HepaRG cells have a higher

212 (Figure 3A).

213 To determine the effect of hepatocyte differentiation on mtDNA methylation, we used the 214 nanopore sequencing protocol described above, comparing progenitor-like HepaRG cells with 
215 their differentiated progeny. In both cases, methylation values were not different from the fully

216 unmethylated control (Figure 3B). There was no differential methylation when directly

217 comparing proliferative and differentiated HepaRG cells (Figure 3C). Similar results were

218 obtained when analyzing both strands together or independently. Interestingly, the likelihood of

219 methylation, as calculated with nanopolish, was higher in differentiated HepaRG cells. This can

220 be seen at the read level (likelihood scale in Figure 3C shows mainly blue reads in proliferative

221 and mainly gray reads in differentiated cells). However, this difference was not high enough to

222 be called as methylation and/or may represent additional nucleotide modifications.

A

RI (refractive index)
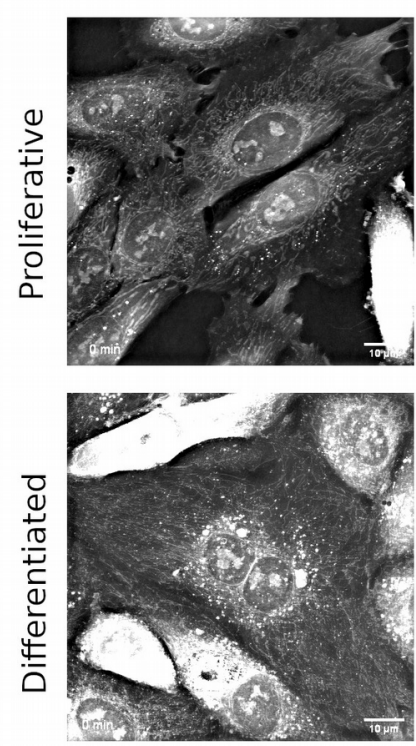

Mito Tracker Green
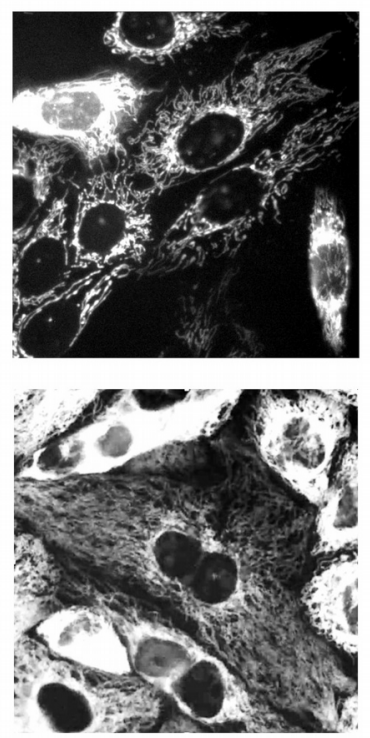

B

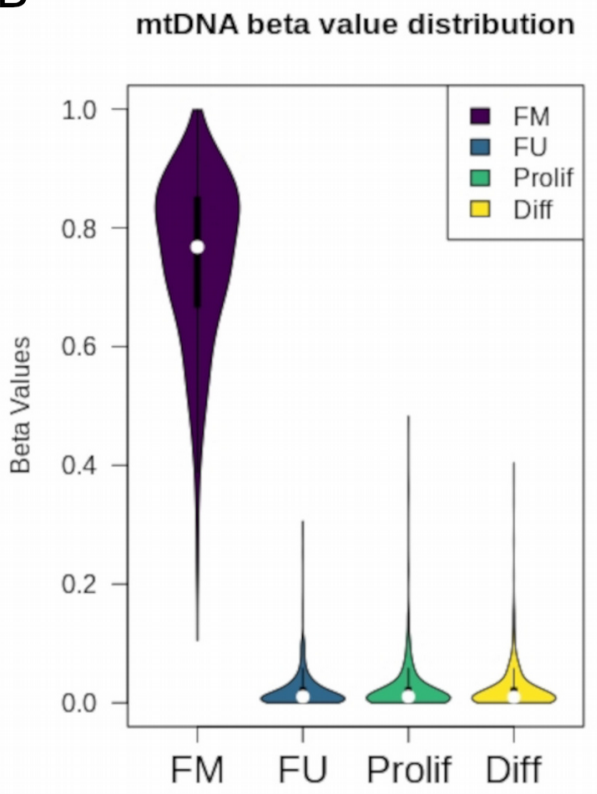

C

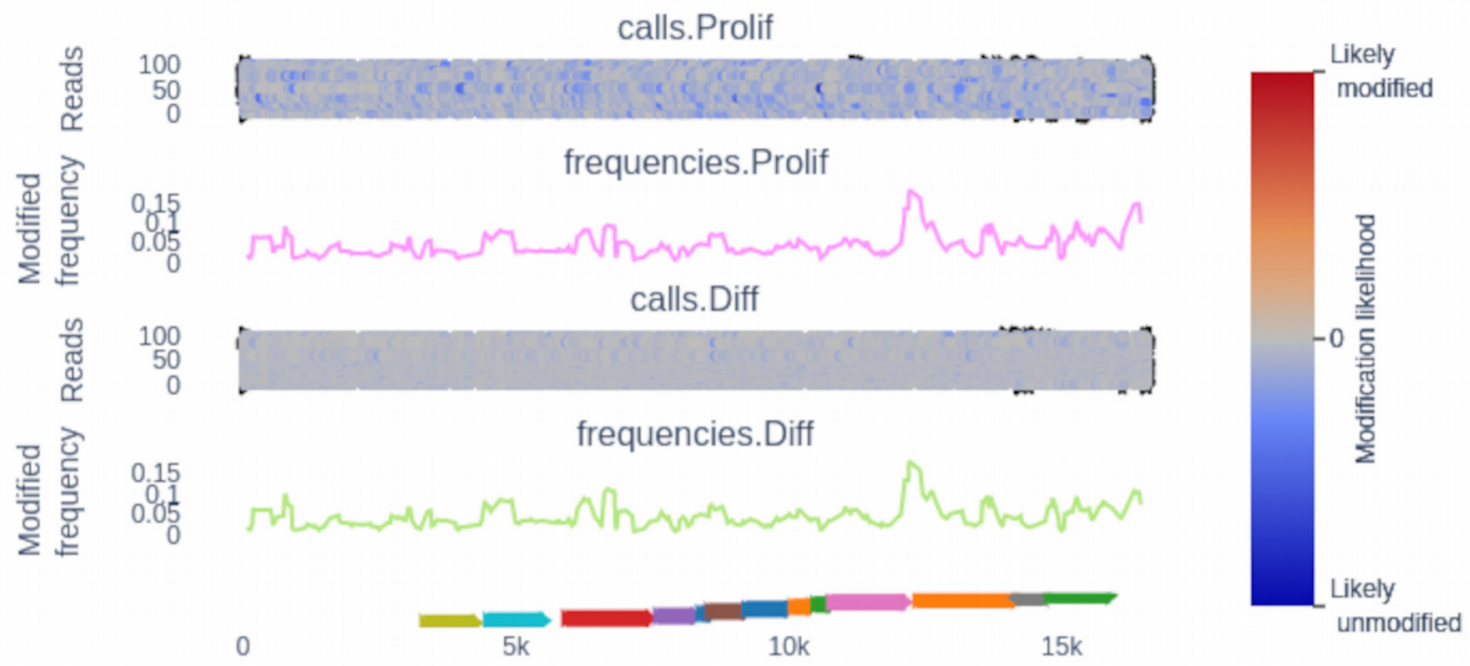


Figure 3. Methylation of mitochondrial DNA measured by nanopore sequencing of a liver progenitor cell line. A) holotomography images of proliferative (progenitor) HepaRG cells and their differentiated progeny. Left panel: Refractive Index (RI) map. Right panel: MitoTracker Green staining to distinguish mitochondrial content and distribution. B) mtDNA enriched DNA extracts from HepaRG cells were linearized and sequenced, as described in Figure $2 A$. The distribution of $5 \mathrm{mCpG}$ beta values (both strands combined) is shown for proliferative (Prolif) and differentiated (Diff) HepaRG, as well as FM and FU controls. C) Methylation frequency and likelihood (pile-plots for the first 100 reads) is shown for proliferative and differentiated HepaRG (one representative sample of three independent differentiation assays). Methylation likelihood scale shown in the pile-plots represents unlikely methylated in blue, likely methylated in red, and intermediate values in gray. Gene mapping to mtDNA are shown in the bottom track as colored arrows.

\section{mtDNA methylation in liver cancer}

Most cancer cells display a switch in their metabolic configuration, primarily relying on aerobic glycolysis instead of mitochondrial oxidative phosphorylation (Vander Heiden et al., 2009). In addition, it was recently described that, mtDNA from liver cancer cells had higher levels of $\mathrm{CpG}$ methylation than that of non-tumorigenic liver cells in vitro (Patil et al., 2019). With this in mind, we wanted to go further and test if mitochondria in vivo exhibit this same pattern of DNA methylation. To this end, we sequenced the mitochondria of ten patient liver tissue samples (normal and tumor matched pairs). Both tumor and non-tumor tissues displayed $5 \mathrm{mCpG}$ methylation above background levels at several CpG sites (Figure 4A). However, we did not find differentially methylated sites when comparing tumor and their matched adjacent tissues (paired, multifactor approach). A subset of $\mathrm{CpG}$ sites with lowest $\mathrm{p}$ values for this comparison (non-adjusted $p<0.05$ ), were able to partially discriminate tumors from non-tumor tissues, with the latter displaying slightly higher levels of $5 \mathrm{mCpG}$ (Figure 4B).

Rather than differential methylation between tumors and non-tumor tissues, we found consistent $5 \mathrm{mCpG}$ at discrete sites (when compared to the FU background control) in both type of samples (Figure 4C). Most $5 \mathrm{mCpG}$ was detected exclusively in the HS (Table), and only 3 CpG sites were consistently found in the LS (i.e. chrM:314, chrM:5469, and chrM:14382). There were also more sites detected as methylated in non-tumor tissues, 
A

FU HepaRG 5mCpG

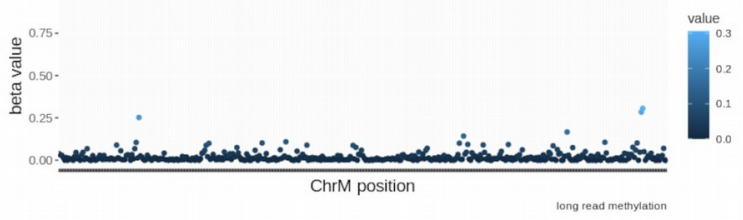

Normal Liver Tissues 5mCpG

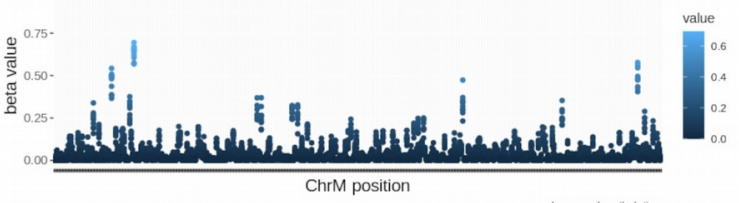

Tumor Liver Tissues 5mCpG

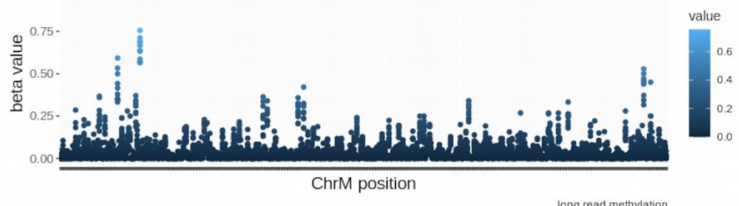

B

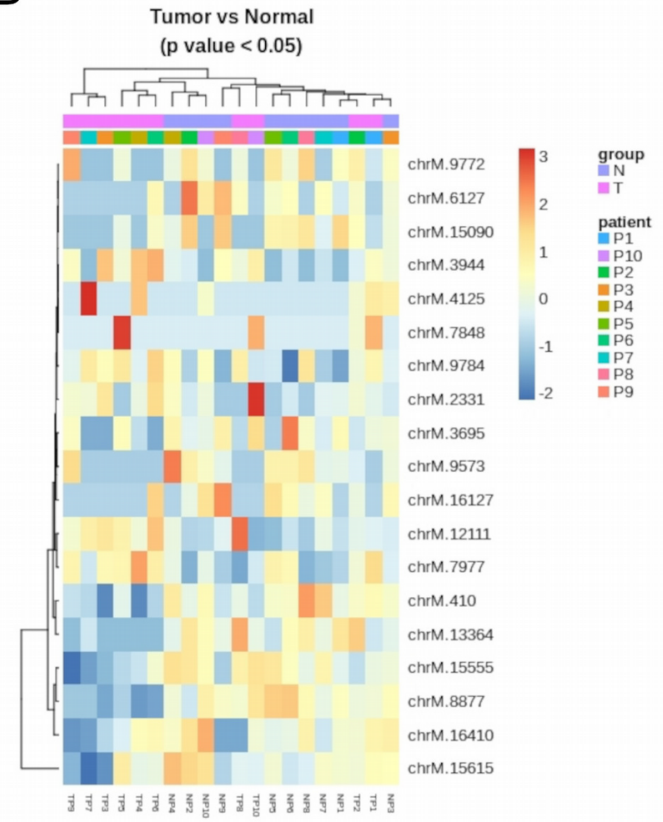

C
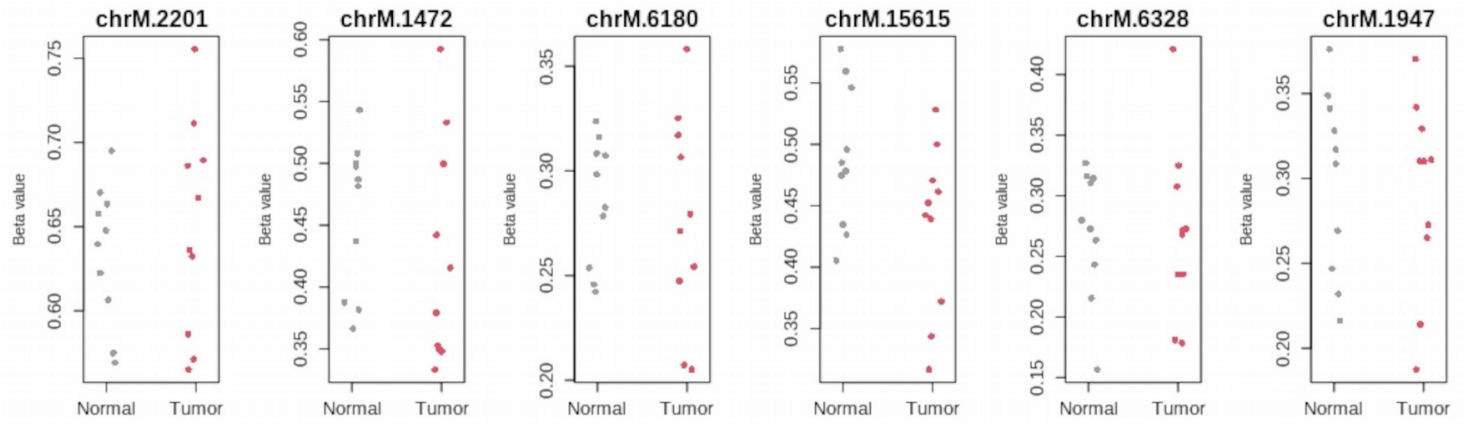

D

\section{$\mathrm{E}$}
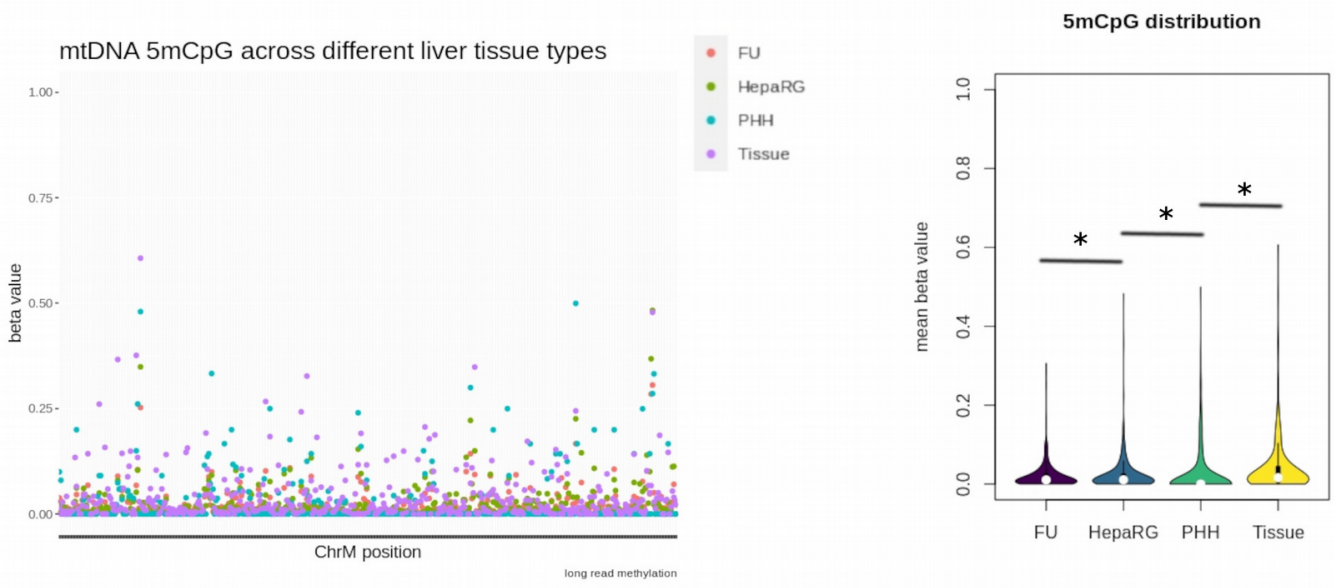
Figure 4. Long read DNA methylation in liver cancer. DNA was extracted from 10 hepatocellular carcinoma (HCC) patients and matched non-tumor adjacent tissues. A) $5 \mathrm{mCpG}$ values are shown after nanopore sequencing of a fully unmethylated (FU) liver cell ine (HepaRG, top panel), 10 non-tumor liver tissues (middle panel), and 10 matched tumor tissues (bottom panel). B) $5 \mathrm{mCpG}$ heatmap of top most significant (lowest $p$ value in the paired Tumor vs. surrounding comparison) CpG sites. Annotations include Tumor (T) vs Normal (N) status, and patient ID (P1 to P10). C) stripchart of 5mCpG (beta values) for those sites displaying higher levels of methylation in tissues relative to the background (FU sample). Each Normal or Tumor sample is represented in gray and red, respectively. D) 5mCpG values along mtDNA for fully unmethylated control (FU), proliferative HepaRG cells, primary human hepatocytes (PHH) and one representative non-tumor liver tissue (Tissue). E) Distribution of mitochondrial $5 \mathrm{mCpG}$ in the same samples represented in (D). $\left(^{*}\right)$ indicates $p$ value $<0.05$, MannWhitney' test.

While the liver cell line HepaRG did not display $5 \mathrm{mCpG}$ above background (Figure 3), liver tissues were consistently methylated at discrete $\mathrm{CpG}$ sites regardless of their tumor/normal status. This suggests that $5 \mathrm{mCpG}$ may be lost in culture conditions. Indeed, major metabolic alterations, notably metabolic repression, has been described after hepatocytes are placed in culture (Cassim et al., 2017). In line with this, we observed intermediate 5mCpG values in primary human hepatocytes $(\mathrm{PHH})$ after two weeks in culture (Figure 4D). Globally, 5mCpG was not different in HepaRG as compared to the FU control $(p=0.5)$. In contrast, $5 \mathrm{mCpG}$ was higher in $\mathrm{PHH}$ relative to HepaRG $(p<2.2 \mathrm{e}-16)$, and higher in liver tissues relative to $\mathrm{PHH}(\mathrm{p}<$ 2.2e-16) (Figure 4E). This result was similar when analyzing separately both mtDNA strands.

Therefore, there are no strong differences in mitochondrial $5 \mathrm{mCpG}$ in tumors relative to their matched normal liver tissues. Instead, we were able to detect consistent $5 \mathrm{mCpG}$ in tissues and a gradual loss in $5 \mathrm{mCpG}$ values as samples are placed in cell culture conditions.

In addition to differentiation and cell transformation, mitochondrial activity is largely associated to oxidative stress, and therefore an interesting process where to study $5 \mathrm{mCpG}$ variation. To induce oxidative stress in vitro, we used an established method utilizing hydrogen peroxide to induce reactive oxygen species (ROS) (Yagi et al., 2013). Several cell lines were tested (data not shown) and Homo sapiens embryonic kidney 293T cells emerged as an ideal candidate for an oxidative stress model. Treatment for two hours was sufficient to induce oxidative stress in 293T cells measured by MitoSox staining, which could be rescued by treatment with $\mathrm{N}$ - 
293 At basal levels, 293T cells exhibited higher global levels of 5mCpG than HepaRG cells ( $p$ value

$294=0.05$ ). However, the same strand specific methylation was observed (i.e. higher 5mCpG in

295 the HS). We then aimed to study the effect of oxidative stress on mtDNA methylation levels. In

296 order to do so, we induced oxidative stress in 293T cells and compared the mtDNA methylation

297 levels before and after treatment. We also rescued these cells from the induced oxidation using

298 NAC. Again we calculated the differential methylation between these three treatment groups

299 and with a threshold of $10 \%$ (Figure 4), we did not observe any differential methylation on the

$300 \mathrm{HS}$ or the LS (Figures $5 \mathrm{C}$ and $5 \mathrm{D}$ ).

301 Although $5 \mathrm{mCpG}$ was clearly detectable in 293T cells, and higher than HepaRG cells, it was

302 not significantly affected by $\mathrm{H} 2 \mathrm{O} 2$ exposure.

303

A

B

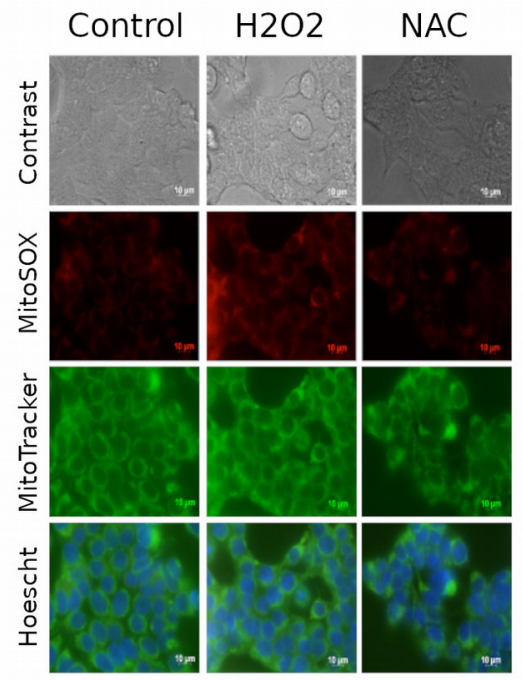

C

1.00- mtDNA 5mCpG under oxidative stress
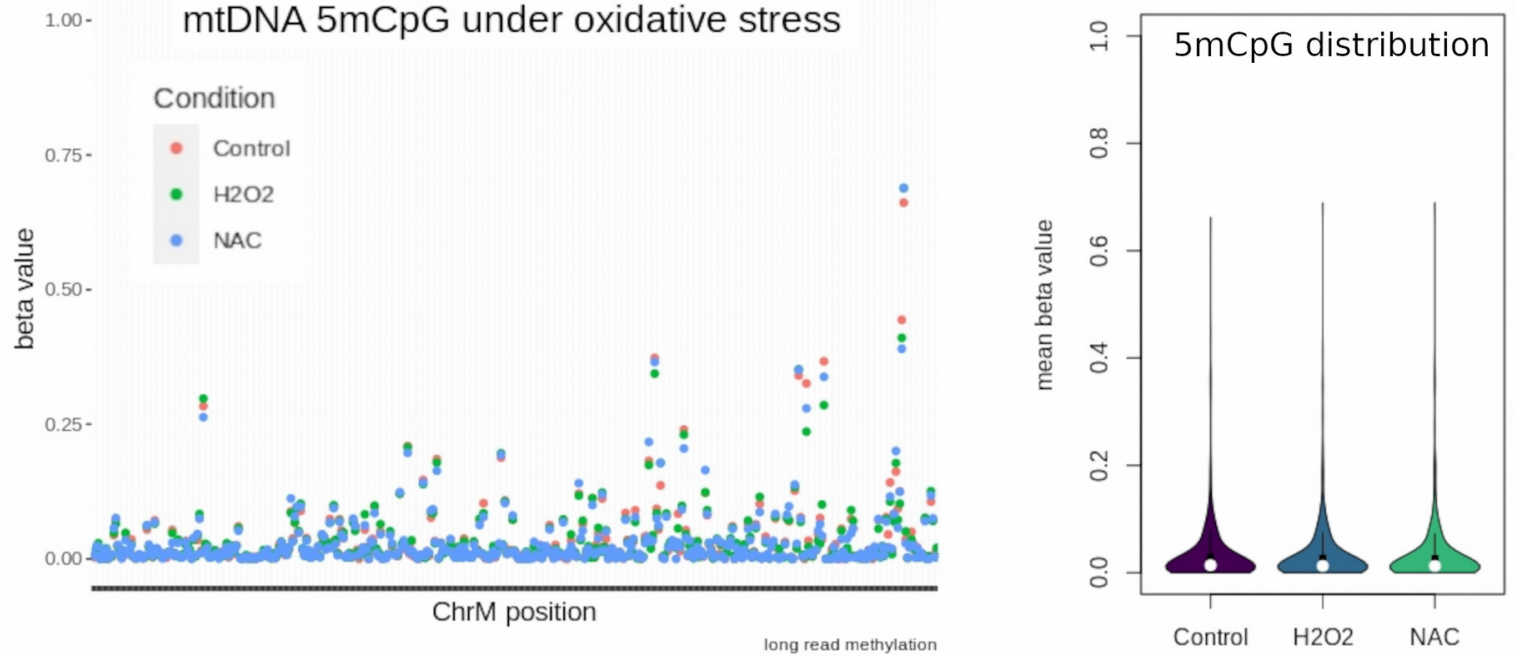
Figure 5. Mitochondrial 5mCpG in response to oxidative stress. Mitochondrial DNA was obtained from the human embryonic kidney cell line 293T under basal conditions (Control), oxidative stress (H2O2) and oxidative stress rescued with $\mathrm{N}$-acetlycysteine (NAC). A) Representative images of phase contrast, Mitosox, MiitoTracker and Hoescht staining. B) MitoSox quantification of 5 independent replicates. C) $5 \mathrm{mCpG}$ measured by nanopore under the same experimental conditions. Each dot represents the average of triplicate values for each condition and each $C p G$ site. D) mitochondrial $5 \mathrm{mCpG}$ distribution (both, HS and LS strands together) of the data shown in (C).

\section{Discussion}

313 In the present study we have shown that nanopore sequencing can reliably detect $5 \mathrm{mCpG}$ in mitochondrial DNA from human cells. Exploiting the advantages of long reads and native DNA sequencing, we show that $5 \mathrm{mCpG}$ can be detected at discrete $\mathrm{CpG}$ locations at levels that depend on the cellular model (i.e. immortalized cell line, primary cells, or tissue). However, we did not observe differential $5 \mathrm{mCpG}$ in three biological contexts: in vitro differentiation of a liver progenitor cell line, comparison of human liver tumors and their matched non-tumor tissues, and in vitro induction of oxidative stress.

320 For the first time, we provide a comprehensive characterization of mtDNA methylation lin liver cells, kidney cells and liver tissue by long read sequencing (ONT). We were able to use this highly novel tool to detect the methylation patterns along $16 \mathrm{~kb}$ reads spanning the entire mitochondrial chromosome with deep coverage of $>10000 x$ on naive DNA. In doing so, we have produced a map of mtDNA $5 \mathrm{mCpG}$, that has completely eliminated any introduced bias from bisulfite conversion and PCR amplification; tools that we have relied on, and that have served us well for many years.

Using ONT, we identified low basal levels of mtDNA methylation at specific regions in liver cells in vitro. These levels were lower than that previously described (Ghosh et al., 2014; Patil et al., 2019), however these authors have noted that CpG methylation was highly cell specific. While we also analyzed the mitochondrial methylome of liver cells, we did not use the same cell lines as these previous studies. Hence, the differences observed are likely due to the cell specific nature of mtDNA $5 \mathrm{mCpG}$. Moreover, it should be noted that a series of work outlining amendments to the bisulfite conversion protocol for mitochondria have been published in order to ensure the bisulfite conversion efficiency is properly controlled for (Owa et al., 2018). Since the average mtDNA CpG methylation levels were very low, we further validated this work through extensive comparisons of basal $5 \mathrm{mCpG}$ with negative controls. Other studies have reported similar cell specific mtDNA methylation patterns (Bellizzi et al., 2013), however, we are the first to represent these landscapes in differentiation models and/or using long reads. 
Furthermore, we have also for the first time, clearly identified strand specific mtDNA methylation using long read sequencing. We observed higher levels of $5 \mathrm{mCpG}$ in the HS generally. This was in accordance with recent reports that have also identified a strand specific methylation via different techniques such as bisulfite sequencing and meDIP (Dou et al., 2019;

343 Ghosh et al., 2014; Patil et al., 2019).

344 We did not find significant variation in $5 \mathrm{mCpG}$ under oxidative stress conditions. While the effect of oxidative stress on mitochondrial activity has been extensively studied (Ashari et al., 2020; Yu et al., 2020), there had not yet been a comprehensive mapping of mtDNA 5mCpG in oxidative stress conditions. In fact, we could not find any work that has investigated mtDNA methylation in this context.

349 Despite our novelty, there are limitations to this work as it stands; including the lack of investigation into non-CpG methylation, which has previously been characterized in liver cancer cells and linked strongly to the control of mitochondrial gene expression (Bellizzi et al., 2013; Patil et al., 2019), as well as the detection of $5 \mathrm{hmCpG}$, which has been also reported in mtDNA (Shock et al., 2011), and is highly dynamic in liver cell differentiation and linked to gene regulation (Ancey et al., 2017; Rodríguez-Aguilera et al., 2020). Therefore, it is clear that more work is needed to develop long read sequencing tools to determine non-CpG methylation or other modified bases like $5 \mathrm{hmC}$ in general. There are technical and bioinformatic limitations to nanopore sequencing currently. But this field is rapidly advancing and as such we are confident that making this data publicly available will continue to contribute to this important work.

359 In conclusion, nanopore is a useful tool for the detection of modified DNA bases on

360 mitochondria, however, care must be taken to consider the HS and LS strands separately as 361 well as the heterogeneity of mitochondrial populations.

\section{Methods}

\section{Cell culture, maintenance and differentiation}

365 HepaRG cells were cultured in Williams media enriched with $10 \%$ Fetal calf serum clone II, $1 \%$ 366 Penicillin/Streptomycin, L-glutamine $(2 \mathrm{mM})$, insulin $(5 \mu \mathrm{g} / \mathrm{mL})$ and hydrocortisone $(25 \mu \mathrm{g} / \mathrm{mL})$.

367 Proliferative HepaRGs were taken before reaching $50 \%$ confluence and differentiated 368 hepaRGs were differentiated as previously described (Ancey et al., 2017; Cerec et al., 2007; 369 Rodríguez-Aguilera et al., 2020).

370 HEK293T, immortal cells derived from embryonic kidney were grown in tissue culture dishes 371 (Falcon, Becton Dickinson) and cultured in DMEM 1X media containing 1\% 
372 Penicillin/Streptomycin, 1\% sodium pyruvate, 1\% L-glutamine, 1\% non-essential amino-acids,

373 all from Life Technologies, and 10\% fetal bovine serum (Eurobio Abcys).

\section{$374 \quad$ Induction of oxidative stress}

375 HEK293T cells were treated ydrogen peroxide (H2O2) (Sigma-Aldrich, 216763) at a concentration 376 of $500 \mu \mathrm{M}$ for 2 hours, alone or in combination with $5 \mathrm{mM} \mathrm{N}$-acetyl-cyteine (NAC) (Sigma-Aldrich,

377 A7250). When using NAC, cells were pre-treated for $2 \mathrm{hrs}$ with 5mM NAC.

378 The mitochondrial superoxide indicator stain MitoSOX (ThermoFisher, M36008) was used to probe 379 the relative oxidative stress in live cells. Cells were stained witiih 1uM MitoSox diluted in DMEM.

380250,000 cells were incubated with 330 ul for 30 min and analyzed by flow cytometry, then washed 381 with PBS and trypsinized. Flow cytometry tubes were kept on ice and in the dark until use. Flow 382 cytometry analysis was performed with a FACSCalibur (BD Biosciences). The mean fluorescence 383 intensity of minimum 10,000 stained cells and unstained control cells were recorded and plotted for 384 analysis. Alternatively, MitoSOX was analyzed by epifluorescence microscopy (Zeiss, Axio 385 Observer).

\section{Holotomography}

387 Differentiated and proliferative HepaRG cells were plated at high confluence. Mitotracker 388 (100nM) was added to normal growth medium for $1 \mathrm{~h}$ before imaging with a 3D Cell-Explorer 389 Fluo (Nanolive, Ecublens, Switzerland) using a 60x air objective. Refractory index maps were 390 generated and images were processed every 5 seconds for 20 minutes with the STEVE 391 software.

\section{Subcellular fractionation and mtDNA extraction}

393 Subcellular fractionation was performed as previously described (Arnoult et al., 2003) with 394 some modifications. Briefly, cells were washed with PBS, harvested by scraping and 395 centrifuged at $1000 \mathrm{~g}$ for $5 \mathrm{~min}$. The pellet was re-suspended in buffer containing $210 \mathrm{mM}$ 396 sorbitol, $70 \mathrm{mM}$ sucrose, $1 \mathrm{mM}$ EDTA, $10 \mathrm{mM}$ HEPES and 0.1\% BSA (Sigma) before grinding 397 with a Dounce Homogenizer (Wheaton, USA) with a loose and tight pestle (100 strokes with 398 each pestle). Cells were observed under microscope (Axiovert 40C, Zeiss) with trypan blue dye 399 to assess cell membrane disruption followed by centrifugation at $500 \mathrm{~g}$ for $5 \mathrm{~min}$ at $4{ }^{\circ} \mathrm{C}$. The 400 supernatant was collected before centrifugation at $10000 \mathrm{~g}$ for $30 \mathrm{~min}$ at $4{ }^{\circ} \mathrm{C}$. DNA extraction 401 (Nucleospin Tissue, Macherey-Nagel) was performed on the resulting pellet according to 402 manufacturer instructions. mtDNA was digested using BamH1 HF (New England BioLabs) in 403 order to linearize mtDNA genome.

\section{$404 \quad$ Fully unmethylated and fully methylated controls}

405 After mtDNA enrichment and linearization, we prepared a negative (FU = fully unmethylated) 
control sample from differentiated HepaRG mtDNA by performing whole genome amplification using a repliG kit (Qiagen) according to manufacturer's instructions. After amplification, a positive control for methylation (FM = fully methylated) was prepared. Briefly, $\mathrm{CpG}$ dinucleotides were methylated by incubating $1 \mu \mathrm{g}$ of DNA with S-Adenosyl methionine (SAM) $(32 \mu \mathrm{M})$ with CpG Methyltransferase (M.Sssl) (4-25 units) (New England BioLabs) at $37^{\circ} \mathrm{C}$ for

$411 \quad 1 \mathrm{~h}$ before heating to $65^{\circ} \mathrm{C}$ for $20 \mathrm{mins}$.

\section{$412 \quad$ Patient tissue samples}

413 Human biological samples and associated data were obtained from "Tissu-Tumorothèque Est" 414 (CRB-HCL, Hospices Civils de Lyon Biobank, BB-0033-00046). DNA extracted with the 415 epicentre kit.

\section{$416 \quad$ Nanopore sequencing}

417 400ng of DNA from each sample or control was barcoded and multiplexed using the Nanopore 418 Rapid Barcoding Sequencing kit (SQK-RBK004) according to manufacturer's instructions.

419 Sequencing was conducted with a Minion sequencer on ONT 1D flow cells (FLO-min106) with 420 protein pore R9.4 1D chemistry for 48h. Reads were basecalled with GUPPY (version 4.3.2).

421 Basecalled reads were mapped using Minimap2 to the GRCh38/hg38 human genome.

\section{$422 \quad$ Bioinformatic analyses}

423 Basecalling was performed with Guppy version 4.0.15 (ONT). We first determined the 424 methylation status of each CpG site on every read by using the widely used tool, nanopolish 425 (Simpson et al., 2017) used recently by (Gigante et al., 2019). For validation, we also called 426 DNA methylation using novel tool, Medaka (git repository reference). Medaka is a tool to create 427 a consensus sequence from nanopore sequencing data. This task is performed using neural 428 networks applied from a pileup of individual sequencing reads against a draft assembly. It outperforms graph-based methods operating on basecalled data, and can be competitive with state-of-the-art signal-based methods, whilst being much faster.

PycoQC was used for data inspection and quality control (https://github.com/a-slide/pycoQC), 433 Called CpG sites in the FU control were used to determine a baseline of methylation. The 434 following calculation was utilised: FalsePositiveRate=[\#called methylated cytosines in $435 \quad \mathrm{FU} / \#$ called cytosines in FU].

436 For differential methylation analyses we used DSS (Dispersion shrinkage for sequencing data) 437 (Park and Wu, 2016) adapted for nanopore sequencing (Gigante et al., 2019). The aggregated $438 \quad \beta$ methylation values for each $\mathrm{CpG}$ group are tested for differential methylation using the DSS 
software (Park and Wu, 2016) and adapted for nanopore sequencing according to (Gigante et al., 2019). Briefly, DSS tests for differential methylation at single CpG-sites, using a Wald test on the co-efficients of a beta-binomial regression of count data with an 'arcsine' link function. In order to set minimum requirements for DSS analysis, an internal comparison of biological replicates of differentiated HepaRG cells was undertaken. From this we were able to better understand the background and determine the minimum smoothing and delta values. These values were set at a smoothing of $10-50 \mathrm{bp}$ and a delta of 0.05 with minimum P-value of 0.05 .

We used the bioconductor packages MIRA (Lawson et al., 2018) for methylation data aggregation, and LOLA for dataset selection (Sheffield and Bock, 2016).

Mann-Whitney's test was used for pairwise comparisons of $5 \mathrm{mCpG}$ distribution.

\section{Availability of data and material}

451 Datasets generated during the current study will be uploaded to the GEO repository.

\section{Competing interests}

454 C.G. and H.H.-V. have received travel and accommodation support to attend conferences for 455 Oxford Nanopore Technology. The authors declare that they have no additional competing 456 interests.

\section{Funding}

459 This work was supported by the Agence Nationale de Recherches sur le SIDA et les Hépatites $460 \quad$ Virales (ANRS, Reference No. ECTZ47287 and ECTZ50137); the Institut National du Cancer 461 AAP PLBIO 2017 (project : T cell tolerance to microbiota and colorectal cancers); La Ligue 462 Nationale Contre Le Cancer Comité d'Auvergne-Rhône-Alpes AAP 2018; Dirección General de 463 Asuntos del Personal Académico/Programa de Apoyo a Proyectos de Investigación e 464 Innovación Tecnológica (DGAPA/PAPIIT-UNAM Grant number IN9082015); PhD Fellowship 465 from Consejo Nacional de Ciencia y Tecnología to JRRA (CONACyT CVU 508509); 466 International Research Internship Support to JRRA from Programa de Apoyo a los Estudios de 467 Posgrado del Programa de Maestría y Doctorado en Ciencias Bioquímicas (PAEP-UNAM No. 468 Cta. 30479367-5), CONACyT (Beca Mixta CVU 508509), Stipend Supplement from IARC 469 (Ref. STU. 2052), and Aide au logement from CAF (No Allocataire: $4384941 \mathrm{~W}$ ) and 470 ROAL660122. 


\section{$472 \quad$ Acknowledgements}

473 The authors would like to thank the patients that participated in this study.

\section{$475 \quad$ Authors' contributions}

476 C.G. carried out the experiments and wrote the first draft of the manuscript; J.R.R.A. and I.E-R.

477 performed experiments and additional validations; C.G., A.J. and H.H.-V. performed all

478 statistical and bioinformatic analyses; V.H. obtained the human samples; R.D., G.I., and

479 V.C.d.S. provided conceptual assistance and supervised experiments; H.H.-V. and G.I.

480 conceived the study; H.H.-V. coordinated the project and wrote the manuscript. All authors

481 discussed the results and manuscript text. 
485 Table. Differential methylation in normal and tumor samples, relative to FU control.

486

487

Normal Liver vs. FU control

HCC vs. FU control

488

CpG site

pval fdr

pval

fdr

489

Heavy Strand

490

chrM:185

chrM:410

5.0E-14

1.1E-12

4.4E-06 5.5E-05

chrM:931

1.5E-07

1.6E-06

3.0E-04 2.3E-03

chrM:934

2.5E-21

1.3E-19

2.0E-18 $1.2 \mathrm{E}-16$

491

chrM:1176

$1.2 \mathrm{E}-16$

3.2E-15

1.0E-17

$5.5 \mathrm{E}-16$

chrM:1472

2.0E-28

$1.5 \mathrm{E}-26$

2.8E-26

4.1E-24

492

2.4E-20 1.2E-18

2.7E-17

1.3E-15

chrM:1474

$8.6 \mathrm{E}-45$

8.7E-38

3.8E-35

493

$7.6 \mathrm{E}-09$

$8.9 \mathrm{E}-08$

chrM:1748

2.6E-09

3.2E-08

chrM:1947

4.4E-07

4.2E-06

chrM:2201

3.5E-07

3.5E-06

chrM:3171

2.1E-19

7.7E-18

chrM:3246

1.8E-07

$1.9 \mathrm{E}-06$

chrM:3965

$7.8 \mathrm{E}-12$

1. $4 \mathrm{E}-10$

chrM:5754

9.9E-12

1.7E-10

1.8E-07

2.8E-06

chrM:6180

3.2E-18

1.1E-16

1.2E-05

1.3E-04

chrM:6328

4.7E-11

$6.8 \mathrm{E}-10$

6.3E-17

2.5E-15

4.7E-09

1.1E-07

chrM:6568

3.2E-18

1.2E-18

1.1E-16

chrM:6571

$5.2 \mathrm{E}-15$

1.4E-13

chrM:6850

8.9E-32

7.7E-30

chrM:7018

1.4E-10

1.9E-09

chrM:7995

1.3E-37

$1.9 \mathrm{E}-35$

chrM:8018

1.9E-15

4.9E-14

chrM:8116

4.4E-17

1.3E-15

chrM:9053

6.9E-08

7.7E-07

5.0E-17

2.2E-15

502

chrM:9161

$1.9 \mathrm{E}-10$

2.5E-09

$1.9 \mathrm{E}-32$

2.0E-30

chrM:9382

6.5E-41

$1.4 \mathrm{E}-38$

2.7E-10

3.4E-09

chrM:11029

$1.4 \mathrm{E}-11$

2.2E-10

chrM:11161

2.3E-05

$1.5 \mathrm{E}-04$

chrM:11475

$1.7 \mathrm{E}-05$

$1.2 \mathrm{E}-04$

chrM:11715

$1.5 \mathrm{E}-08$

$1.8 \mathrm{E}-07$

chrM:11912

$8.1 \mathrm{E}-07$

7.4E-06

chrM:14696

$5.0 \mathrm{E}-13$

1.0E-11

6.1E-06

7.0E-05

chrM:15615

3.4E-04

$1.9 \mathrm{E}-03$

1.4E-15

$5.1 \mathrm{E}-14$

$1.2 \mathrm{E}-08 \quad 2.5 \mathrm{E}-07$

chrM:15925

4.5E-06

3.5E-05

5.5E-06

6.6E-05

1.0E-08 2.2E-07

3.3E-25 3.6E-23

7.3E-32 1.6E-29

6.4E-10 1.6E-08

509

Light Strand

510

\begin{tabular}{cclcc} 
CpG site & pval & \multicolumn{1}{c}{ fdr } & pval & fdr \\
\hline chrM:314 & $1.5 \mathrm{E}-18$ & $6.4 \mathrm{E}-16$ & $1.3 \mathrm{E}-07$ & $2.8 \mathrm{E}-05$ \\
chrM:4425 & $2.9 \mathrm{E}-07$ & $1.1 \mathrm{E}-05$ & - & - \\
chrM:5469 & $9.1 \mathrm{E}-07$ & $3.0 \mathrm{E}-0520$ & $1.6 \mathrm{E}-05$ & $1.0 \mathrm{E}-03$ \\
chrM:14382 & $6.9 \mathrm{E}-18$ & $1.5 \mathrm{E}-15$ & $5.8 \mathrm{E}-12$ & $2.5 \mathrm{E}-09$ \\
\hline
\end{tabular}




\section{$511 \quad$ References}

Alberts, B., Johnson, A., Lewis, J., Raff, M., Roberts, K., Walter, P., 2002. Molecular Biology of the Cell, 4th ed. Garland Science.

Alexeyev, M., Shokolenko, I., Wilson, G., LeDoux, S., 2013. The Maintenance of Mitochondrial DNA Integrity-Critical Analysis and Update. Cold Spring Harb Perspect Biol 5. https://doi.org/10.1101/cshperspect.a012641

Ancey, P.-B., Ecsedi, S., Lambert, M.-P., Talukdar, F.R., Cros, M.-P., Glaise, D., Narvaez, D.M., Chauvet, V., Herceg, Z., Corlu, A., Hernandez-Vargas, H., 2017. TET-Catalyzed 5-Hydroxymethylation Precedes HNF4A Promoter Choice during Differentiation of Bipotent Liver Progenitors. Stem Cell Reports 9, 264-278. https://doi.org/10.1016/j.stemcr.2017.05.023

Arnoult, D., Gaume, B., Karbowski, M., Sharpe, J.C., Cecconi, F., Youle, R.J., 2003. Mitochondrial release of AIF and EndoG requires caspase activation downstream of Bax/Bak-mediated permeabilization. EMBO J. 22, 4385-4399. https://doi.org/10.1093/emboj/cdg423

Ashari, S., Karami, M., Shokrzadeh, M., Ghandadi, M., Ghassemi-Barghi, N., Dashti, A., Ranaee, M., Mohammadi, H., 2020. The implication of mitochondrial dysfunction and mitochondrial oxidative damage in di (2-ethylhexyl) phthalate induced nephrotoxicity in both in vivo and in vitro models. Toxicol. Mech. Methods 30, 427-437. https://doi.org/10.1080/15376516.2020.1758980

Bellizzi, D., D'Aquila, P., Scafone, T., Giordano, M., Riso, V., Riccio, A., Passarino, G., 2013. The control region of mitochondrial DNA shows an unusual CpG and non-CpG methylation pattern. DNA Res. 20, 537-547.

https://doi.org/10.1093/dnares/dst029

Cassim, S., Raymond, V.-A., Lapierre, P., Bilodeau, M., 2017. From in vivo to in vitro: Major metabolic alterations take place in hepatocytes during and following isolation. PLoS ONE 12, e0190366. https://doi.org/10.1371/journal.pone.0190366

Cerec, V., Glaise, D., Garnier, D., Morosan, S., Turlin, B., Drenou, B., Gripon, P., Kremsdorf, D., Guguen-Guillouzo, C., Corlu, A., 2007. Transdifferentiation of hepatocyte-like cells from the human hepatoma HepaRG cell line through bipotent progenitor. Hepatology 45, 957-967. https://doi.org/10.1002/hep.21536

Crews, S., Ojala, D., Posakony, J., Nishiguchi, J., Attardi, G., 1979. Nucleotide sequence of a region of human mitochondrial DNA containing the precisely identified origin of replication. Nature 277, 192-198.

https://doi.org/10.1038/277192a0

Dou, X., Boyd-Kirkup, J.D., McDermott, J., Zhang, X., Li, F., Rong, B., Zhang, R., Miao, B., Chen, P., Cheng, H., Xue, J., Bennett, D., Wong, J., Lan, F., Han, J.-D.J., 2019. The strand-biased mitochondrial DNA methylome and its regulation by DNMT3A. Genome Res. 29, 1622-1634. https://doi.org/10.1101/gr.234021.117

Fish, J., Raule, N., Attardi, G., 2004. Discovery of a major D-loop replication origin reveals two modes of human mtDNA synthesis. Science 306, 2098-2101. https:// doi.org/10.1126/science.1102077 
Ghosh, S., Sengupta, S., Scaria, V., 2014. Comparative analysis of human mitochondrial methylomes shows distinct patterns of epigenetic regulation in mitochondria. Mitochondrion 18, 58-62.

https://doi.org/10.1016/j.mito.2014.07.007

Gigante, S., Gouil, Q., Lucattini, A., Keniry, A., Beck, T., Tinning, M., Gordon, L., Woodruff, C., Speed, T.P., Blewitt, M.E., Ritchie, M.E., 2019. Using long-read sequencing to detect imprinted DNA methylation. Nucleic Acids Res. 47, e46. https://doi.org/10.1093/nar/gkz107

Gilpatrick, T., Lee, I., Graham, J.E., Raimondeau, E., Bowen, R., Heron, A., Downs, B., Sukumar, S., Sedlazeck, F.J., Timp, W., 2020. Targeted nanopore sequencing with Cas9-guided adapter ligation. Nat. Biotechnol. 38, 433-438.

https://doi.org/10.1038/s41587-020-0407-5

Hong, E.E., Okitsu, C.Y., Smith, A.D., Hsieh, C.-L., 2013. Regionally specific and genome-wide analyses conclusively demonstrate the absence of CpG methylation in human mitochondrial DNA. Mol. Cell. Biol. 33, 2683-2690. https:// doi.org/10.1128/MCB.00220-13

Jain, M., Olsen, H.E., Paten, B., Akeson, M., 2016. The Oxford Nanopore MinION: delivery of nanopore sequencing to the genomics community. Genome Biol. 17, 239. https://doi.org/10.1186/s13059-016-1103-0

Lawson, J.T., Tomazou, E.M., Bock, C., Sheffield, N.C., 2018. MIRA: an R package for DNA methylation-based inference of regulatory activity. Bioinformatics 34, 2649-2650. https://doi.org/10.1093/bioinformatics/bty083

Li, Y., Tollefsbol, T.O., 2011. DNA methylation detection: bisulfite genomic sequencing analysis. Methods Mol. Biol. 791, 11-21. https://doi.org/10.1007/9781-61779-316-5_2

Lieber, C.S., 1991. Hepatic, metabolic and toxic effects of ethanol: 1991 update. Alcohol. Clin. Exp. Res. 15, 573-592. https://doi.org/10.1111/j.1530-

0277.1991.tb00563.x

Madoui, M.-A., Engelen, S., Cruaud, C., Belser, C., Bertrand, L., Alberti, A., Lemainque, A., Wincker, P., Aury, J.-M., 2015. Genome assembly using Nanoporeguided long and error-free DNA reads. BMC Genomics 16, 327.

https://doi.org/10.1186/s12864-015-1519-z

Mechta, M., Ingerslev, L.R., Fabre, O., Picard, M., Barrès, R., 2017. Evidence Suggesting Absence of Mitochondrial DNA Methylation. Front Genet 8, 166. https://doi.org/10.3389/fgene.2017.00166

Owa, C., Poulin, M., Yan, L., Shioda, T., 2018. Technical adequacy of bisulfite sequencing and pyrosequencing for detection of mitochondrial DNA methylation: Sources and avoidance of false-positive detection. PLoS ONE 13, e0192722. https://doi.org/10.1371/journal.pone.0192722

Patil, V., Cuenin, C., Chung, F., Aguilera, J.R.R., Fernandez-Jimenez, N., RomeroGarmendia, I., Bilbao, J.R., Cahais, V., Rothwell, J., Herceg, Z., 2019. Human mitochondrial DNA is extensively methylated in a non-CpG context. Nucleic Acids 
Res. 47, 10072-10085. https://doi.org/10.1093/nar/gkz762

Porporato, P.E., Filigheddu, N., Pedro, J.M.B.-S., Kroemer, G., Galluzzi, L., 2018. Mitochondrial metabolism and cancer. Cell Res. 28, 265-280.

https://doi.org/10.1038/cr.2017.155

Rodríguez-Aguilera, J.R., Ecsedi, S., Goldsmith, C., Cros, M.-P., Domínguez-López, M., Guerrero-Celis, N., Pérez-Cabeza de Vaca, R., Chemin, I., Recillas-Targa, F., Chagoya de Sánchez, V., Hernández-Vargas, H., 2020. Genome-wide 5hydroxymethylcytosine $(5 \mathrm{hmC})$ emerges at early stage of in vitro differentiation of a putative hepatocyte progenitor. Sci Rep 10, 7822.

https://doi.org/10.1038/s41598-020-64700-2

Seki, M., Katsumata, E., Suzuki, A., Sereewattanawoot, S., Sakamoto, Y., Mizushima-Sugano, J., Sugano, S., Kohno, T., Frith, M.C., Tsuchihara, K., Suzuki, Y., 2019. Evaluation and application of RNA-Seq by MinION. DNA Res. 26, 55-65. https://doi.org/10.1093/dnares/dsy038

Sheffield, N.C., Bock, C., 2016. LOLA: enrichment analysis for genomic region sets and regulatory elements in $\mathrm{R}$ and Bioconductor. Bioinformatics 32, 587-589. https://doi.org/10.1093/bioinformatics/btv612

Simpson, J.T., Workman, R.E., Zuzarte, P.C., David, M., Dursi, L.J., Timp, W., 2017. Detecting DNA cytosine methylation using nanopore sequencing. Nat. Methods 14, 407-410. https://doi.org/10.1038/nmeth.4184

Sun, X., St John, J.C., 2018. Modulation of mitochondrial DNA copy number in a model of glioblastoma induces changes to DNA methylation and gene expression of the nuclear genome in tumours. Epigenetics Chromatin 11, 53. https://doi.org/ $10.1186 / s 13072-018-0223-z$

Vander Heiden, M.G., Cantley, L.C., Thompson, C.B., 2009. Understanding the Warburg effect: the metabolic requirements of cell proliferation. Science 324, 1029-1033. https://doi.org/10.1126/science.1160809

Weinhouse, C., 2017. Mitochondrial-epigenetic crosstalk in environmental toxicology. Toxicology 391, 5-17. https://doi.org/10.1016/j.tox.2017.08.008

Wick, R.R., Judd, L.M., Holt, K.E., 2019. Performance of neural network basecalling tools for Oxford Nanopore sequencing. Genome Biol. 20, 129. https:// doi.org/10.1186/s13059-019-1727-y

Yagi, H., Tan, J., Tuan, R.S., 2013. Polyphenols suppress hydrogen peroxideinduced oxidative stress in human bone-marrow derived mesenchymal stem cells. J. Cell. Biochem. 114, 1163-1173. https://doi.org/10.1002/jcb.24459

Yu, Y., Liu, H., Ikeda, Y., Amiot, B.P., Rinaldo, P., Duncan, S.A., Nyberg, S.L., 2012. Hepatocyte-like cells differentiated from human induced pluripotent stem cells: relevance to cellular therapies. Stem Cell Res 9, 196-207. https://doi.org/10.1016/j.scr.2012.06.004

Alberts, B., Johnson, A., Lewis, J., Raff, M., Roberts, K., Walter, P., 2002. Molecular Biology of the Cell, 4th ed. Garland Science. 
Alexeyev, M., Shokolenko, I., Wilson, G., LeDoux, S., 2013. The Maintenance of Mitochondrial DNA Integrity-Critical Analysis and Update. Cold Spring Harb Perspect Biol 5. https://doi.org/10.1101/cshperspect.a012641

Ancey, P.-B., Ecsedi, S., Lambert, M.-P., Talukdar, F.R., Cros, M.-P., Glaise, D., Narvaez, D.M., Chauvet, V., Herceg, Z., Corlu, A., Hernandez-Vargas, H., 2017. TET-Catalyzed 5-Hydroxymethylation Precedes HNF4A Promoter Choice during Differentiation of Bipotent Liver Progenitors. Stem Cell Reports 9, 264-278. https://doi.org/10.1016/j.stemcr.2017.05.023

Arnoult, D., Gaume, B., Karbowski, M., Sharpe, J.C., Cecconi, F., Youle, R.J., 2003. Mitochondrial release of AIF and EndoG requires caspase activation downstream of Bax/Bak-mediated permeabilization. EMBO J. 22, 4385-4399.

https://doi.org/10.1093/emboj/cdg423

Ashari, S., Karami, M., Shokrzadeh, M., Ghandadi, M., Ghassemi-Barghi, N., Dashti, A., Ranaee, M., Mohammadi, H., 2020. The implication of mitochondrial dysfunction and mitochondrial oxidative damage in di (2-ethylhexyl) phthalate induced nephrotoxicity in both in vivo and in vitro models. Toxicol. Mech. Methods 30, 427-437. https://doi.org/10.1080/15376516.2020.1758980

Bellizzi, D., D’Aquila, P., Scafone, T., Giordano, M., Riso, V., Riccio, A., Passarino, G., 2013. The control region of mitochondrial DNA shows an unusual CpG and non-CpG methylation pattern. DNA Res. 20, 537-547.

https://doi.org/10.1093/dnares/dst029

Cassim, S., Raymond, V.-A., Lapierre, P., Bilodeau, M., 2017. From in vivo to in vitro: Major metabolic alterations take place in hepatocytes during and following isolation. PLoS ONE 12, e0190366. https://doi.org/10.1371/journal.pone.0190366

Cerec, V., Glaise, D., Garnier, D., Morosan, S., Turlin, B., Drenou, B., Gripon, P., Kremsdorf, D., Guguen-Guillouzo, C., Corlu, A., 2007. Transdifferentiation of hepatocyte-like cells from the human hepatoma HepaRG cell line through bipotent progenitor. Hepatology 45, 957-967. https://doi.org/10.1002/hep.21536

Crews, S., Ojala, D., Posakony, J., Nishiguchi, J., Attardi, G., 1979. Nucleotide sequence of a region of human mitochondrial DNA containing the precisely identified origin of replication. Nature 277, 192-198.

https://doi.org/10.1038/277192a0

Dou, X., Boyd-Kirkup, J.D., McDermott, J., Zhang, X., Li, F., Rong, B., Zhang, R., Miao, B., Chen, P., Cheng, H., Xue, J., Bennett, D., Wong, J., Lan, F., Han, J.-D.J., 2019. The strand-biased mitochondrial DNA methylome and its regulation by DNMT3A. Genome Res. 29, 1622-1634. https://doi.org/10.1101/gr.234021.117

Feng, S., Xiong, L., Ji, Z., Cheng, W., Yang, H., 2012. Correlation between increased ND2 expression and demethylated displacement loop of mtDNA in colorectal cancer. Mol Med Rep 6, 125-130.

https://doi.org/10.3892/mmr.2012.870

Fish, J., Raule, N., Attardi, G., 2004. Discovery of a major D-loop replication origin reveals two modes of human mtDNA synthesis. Science 306, 2098-2101. https:// 
doi.org/10.1126/science.1102077

Ghosh, S., Sengupta, S., Scaria, V., 2014. Comparative analysis of human mitochondrial methylomes shows distinct patterns of epigenetic regulation in mitochondria. Mitochondrion 18, 58-62.

https://doi.org/10.1016/j.mito.2014.07.007

Gigante, S., Gouil, Q., Lucattini, A., Keniry, A., Beck, T., Tinning, M., Gordon, L., Woodruff, C., Speed, T.P., Blewitt, M.E., Ritchie, M.E., 2019. Using long-read sequencing to detect imprinted DNA methylation. Nucleic Acids Res. 47, e46. https://doi.org/10.1093/nar/gkz107

Gilpatrick, T., Lee, I., Graham, J.E., Raimondeau, E., Bowen, R., Heron, A., Downs, B., Sukumar, S., Sedlazeck, F.J., Timp, W., 2020. Targeted nanopore sequencing with Cas9-guided adapter ligation. Nat. Biotechnol. 38, 433-438.

https://doi.org/10.1038/s41587-020-0407-5

Hong, E.E., Okitsu, C.Y., Smith, A.D., Hsieh, C.-L., 2013. Regionally specific and genome-wide analyses conclusively demonstrate the absence of CpG methylation in human mitochondrial DNA. Mol. Cell. Biol. 33, 2683-2690. https:// doi.org/10.1128/MCB.00220-13

Jain, M., Olsen, H.E., Paten, B., Akeson, M., 2016. The Oxford Nanopore MinION: delivery of nanopore sequencing to the genomics community. Genome Biol. 17, 239. https://doi.org/10.1186/s13059-016-1103-0

Lawson, J.T., Tomazou, E.M., Bock, C., Sheffield, N.C., 2018. MIRA: an R package for DNA methylation-based inference of regulatory activity. Bioinformatics 34 , 2649-2650. https://doi.org/10.1093/bioinformatics/bty083

Li, Y., Tollefsbol, T.O., 2011. DNA methylation detection: bisulfite genomic sequencing analysis. Methods Mol. Biol. 791, 11-21. https://doi.org/10.1007/9781-61779-316-5_2

Lieber, C.S., 1991. Hepatic, metabolic and toxic effects of ethanol: 1991 update. Alcohol. Clin. Exp. Res. 15, 573-592. https://doi.org/10.1111/j.15300277.1991.tb00563.x

Madoui, M.-A., Engelen, S., Cruaud, C., Belser, C., Bertrand, L., Alberti, A., Lemainque, A., Wincker, P., Aury, J.-M., 2015. Genome assembly using Nanoporeguided long and error-free DNA reads. BMC Genomics 16, 327. https://doi.org/10.1186/s12864-015-1519-z

Mechta, M., Ingerslev, L.R., Fabre, O., Picard, M., Barrès, R., 2017. Evidence Suggesting Absence of Mitochondrial DNA Methylation. Front Genet 8, 166. https://doi.org/10.3389/fgene.2017.00166

Owa, C., Poulin, M., Yan, L., Shioda, T., 2018. Technical adequacy of bisulfite sequencing and pyrosequencing for detection of mitochondrial DNA methylation: Sources and avoidance of false-positive detection. PLoS ONE 13, e0192722. https://doi.org/10.1371/journal.pone.0192722

Patil, V., Cuenin, C., Chung, F., Aguilera, J.R.R., Fernandez-Jimenez, N., Romero- 
Garmendia, I., Bilbao, J.R., Cahais, V., Rothwell, J., Herceg, Z., 2019. Human mitochondrial DNA is extensively methylated in a non-CpG context. Nucleic Acids Res. 47, 10072-10085. https://doi.org/10.1093/nar/gkz762

Pirola, C.J., Gianotti, T.F., Burgueño, A.L., Rey-Funes, M., Loidl, C.F., Mallardi, P., Martino, J.S., Castaño, G.O., Sookoian, S., 2013. Epigenetic modification of liver mitochondrial DNA is associated with histological severity of nonalcoholic fatty liver disease. Gut 62, 1356-1363. https://doi.org/10.1136/gutjnl-2012-302962

Porporato, P.E., Filigheddu, N., Pedro, J.M.B.-S., Kroemer, G., Galluzzi, L., 2018. Mitochondrial metabolism and cancer. Cell Res. 28, 265-280.

https://doi.org/10.1038/cr.2017.155

Rodríguez-Aguilera, J.R., Ecsedi, S., Goldsmith, C., Cros, M.-P., Domínguez-López, M., Guerrero-Celis, N., Pérez-Cabeza de Vaca, R., Chemin, I., Recillas-Targa, F., Chagoya de Sánchez, V., Hernández-Vargas, H., 2020. Genome-wide 5hydroxymethylcytosine $(5 \mathrm{hmC})$ emerges at early stage of in vitro differentiation of a putative hepatocyte progenitor. Sci Rep 10, 7822.

https://doi.org/10.1038/s41598-020-64700-2

Seki, M., Katsumata, E., Suzuki, A., Sereewattanawoot, S., Sakamoto, Y., Mizushima-Sugano, J., Sugano, S., Kohno, T., Frith, M.C., Tsuchihara, K., Suzuki, Y., 2019. Evaluation and application of RNA-Seq by MinION. DNA Res. 26, 55-65. https://doi.org/10.1093/dnares/dsy038

Sheffield, N.C., Bock, C., 2016. LOLA: enrichment analysis for genomic region sets and regulatory elements in $\mathrm{R}$ and Bioconductor. Bioinformatics 32, 587-589. https://doi.org/10.1093/bioinformatics/btv612

Shock, L.S., Thakkar, P.V., Peterson, E.J., Moran, R.G., Taylor, S.M., 2011. DNA methyltransferase 1, cytosine methylation, and cytosine hydroxymethylation in mammalian mitochondria. Proc. Natl. Acad. Sci. U.S.A. 108, 3630-3635. https://doi.org/10.1073/pnas.1012311108

Simpson, J.T., Workman, R.E., Zuzarte, P.C., David, M., Dursi, L.J., Timp, W., 2017. Detecting DNA cytosine methylation using nanopore sequencing. Nat. Methods 14, 407-410. https://doi.org/10.1038/nmeth.4184

Sun, X., St John, J.C., 2018. Modulation of mitochondrial DNA copy number in a model of glioblastoma induces changes to DNA methylation and gene expression of the nuclear genome in tumours. Epigenetics Chromatin 11, 53. https://doi.org/ $10.1186 / \mathrm{s} 13072-018-0223-\mathrm{z}$

Vander Heiden, M.G., Cantley, L.C., Thompson, C.B., 2009. Understanding the Warburg effect: the metabolic requirements of cell proliferation. Science 324, 1029-1033. https://doi.org/10.1126/science.1160809

Weinhouse, C., 2017. Mitochondrial-epigenetic crosstalk in environmental toxicology. Toxicology 391, 5-17. https://doi.org/10.1016/j.tox.2017.08.008

Wick, R.R., Judd, L.M., Holt, K.E., 2019. Performance of neural network basecalling tools for Oxford Nanopore sequencing. Genome Biol. 20, 129. https:// doi.org/10.1186/s13059-019-1727-y 
Yagi, H., Tan, J., Tuan, R.S., 2013. Polyphenols suppress hydrogen peroxideinduced oxidative stress in human bone-marrow derived mesenchymal stem cells. J. Cell. Biochem. 114, 1163-1173. https://doi.org/10.1002/jcb.24459

Yu, Y., Liu, H., Ikeda, Y., Amiot, B.P., Rinaldo, P., Duncan, S.A., Nyberg, S.L., 2012. Hepatocyte-like cells differentiated from human induced pluripotent stem cells: relevance to cellular therapies. Stem Cell Res 9, 196-207. https://doi.org/10.1016/j.scr.2012.06.004

Yu, Z., Li, Q., Wang, Y., Li, P., 2020. A potent protective effect of baicalein on liver injury by regulating mitochondria-related apoptosis. Apoptosis 25, 412-425. https://doi.org/10.1007/s10495-020-01608-2 